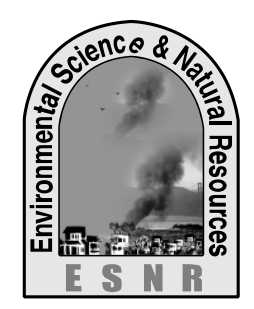

\title{
A Study on Understanding the Relationship between Predisposing and Enabling Factors on Nutritional Status among Secondary School Students
}

\author{
M. A. Hoque, A. Afzal*, T. Nasrin and A. I. Mafiz \\ Department of Food Technology and Nutritional Science, \\ Mawlana Bhashani Science and Technology University, Tangail-1902, Bangladesh \\ "Corresponding author: afsana.ftns2010@gmail.com
}

\begin{abstract}
Child malnutrition coexists in households and communities in Bangladesh due to illiteracy, poverty and knowledge which leading to a risk of disease and mortality. This study is a descriptive cross sectional study, which assessed nutritional status and related factors among high school children. In this study only $52.5 \%$ of respondents had a healthy weight. While $45 \%$ were underweight and $2.5 \%$ were overweight. The relationship between nutritional status and some independent variables at $5 \%$ level of significance were birth order $(P=0.003)$, snacking habit $(P=0.000)$, taking care of respondents $(P=0.007)$, fathers' occupation $(P=0.019)$, mothers' education $(P=0.007)$, earning person of the family $(P=0.028)$ and money for snacking $(P=0.020)$. Based on results, it's suggested that periodical monitoring and evaluation of nutritional status of the students should focus on underweight students. Supplementary support from school is still needed, to assist daily intake of students still underweight especially. Health and nutrition education should be taught.
\end{abstract}

Key words: BMI, Enabling factor, Nutritional status, Predisposing factor, Secondary school students

\section{Introduction}

Malnutrition is widespread problem and affects large number of people in developing countries. Vulnerable populations like school children are susceptible to health problems associated with micronutrient deficiencies. Malnutrition in children is the largest contributor to global burden of disease and causing heavy health expenditures in developing countries especially in Asia. In Asia, it was common in preschool children from $16.0 \%$ in China to $64.0 \%$ in Bangladesh (Khor, 2003). A study conducted in BANGLADESH by Bangladesh Bureau of Statistics and UNICEF it had found that using the new WHO (2005) GRS, $40 \%$ of children aged $<5$ years were underweight. According to criteria of the World Health Organization, the prevalence of Underweight and stunting was "very high". Severe underweight were found in $11 \%$ of the population. In comparison with the urban population, the rural Population was significantly more underweight (42\% vs. 30\%) (CMNSB, 2005). In a second study stunting was also found to increase with age where younger school student were reported to have a prevalence of just $2 \%$ compared to $16 \%$ among older school children in Bangladesh (Ahmed, 2005). UNICEF (1990) said that one in every four children under-five (including 146 million children in the developing world) is underweight. Childhood malnutrition is associated with a number of socioeconomic and environmental characteristics such as poverty, parents' education/occupation, and access to health care services (Delpeuch et al., 2000). The strong relationship between socio-demographic factors and secular growth was shown in some studies (Musaiger, 2004). Among population groups who have experienced constraint on economic and social development and factors affecting the physical growth of school children before puberty are environmental, e.g., poor food consumption pattern, illness, lack of sanitation, poor hygienic practice, food safety and women's education (UNICEF, 1990). The prevalence of underweight, stunting and wasting was significantly higher among mothers with low education status (CMNSB, 2005). A small state of Kerala in India, it has the highest rate of female literacy $87.86 \%$ compared to $54.16 \%$ for all India (Got, India, 2002). Kerala's infant mortality rate is 15.3 per 1,000 births versus 57.0 for India (Suryanarayana, 2008). Malnutrition adversely affects physical and mental growth of children. So this study was aimed to identify nutritional status of children and to discover the factors which related with nutritional status. This study gives the prevalence of malnutrition and associated factors at countryside region in Bangladesh.

\section{Materials and Methods}

\section{Study site}

This study was carried out at Santosh Janhabhi High School in Tangail town for a period of three months from September to November 2013.

\section{Study design}

This study was descriptive cross sectional study.

\section{Study population}

The study population was the 10 grade students of Santosh Jhannobi High School of the Santosh village of Tangail Sadar.

\section{Sample size}

There were 200 class grade 10 students of selected school. Among them we selected 120 students for our study.

\section{Sampling}

Purposive sampling technique was used.

\section{Study type}

Mixed method both quantitative and qualitative.

\section{Development of questionnaire}

A structured questionnaire was used for data collection. Initially, the questionnaire was prepared in English by the researcher, to collecting data. The questionnaire mostly multiple choice questions and some like snacking habit, religion, height, weight, BMI, money 
spend for snacking and earning person of family. The questionnaire contains 3 parts as follows Socio demographic factors, knowledge toward health and nutrition and Enabling factors regarding on nutritional status.

\section{Test of validity and reliability}

Before data collection, the questionnaire was pre-tested for validity and reliability. The questionnaire was adapted according to the comment and suggestion from by the expert.

\section{Collection of data}

Questionnaire was asked passively and cautiously not to influence the respondents. Socio-economic status (SES) data, health and nutritional knowledge, other data of the children's and their families were collected by using standardized questionnaire.

\section{Collection of anthropometric data}

Height and weight of the students were collected based on standard methods (WHO, 2003). Omron digital weighing machine and Fujita stadiometer were used for measuring weight and height respectively. A bathroom scale was used to measure body weight of the study respondents. Weight was measured up to $100 \mathrm{~g}$ and height was measured up to $0.1 \mathrm{~cm}$ fractions. After measuring weight and height BMI was calculated by using the following formula: weight in $\mathrm{kg}$ divided by height in $\mathrm{m}^{2}=\mathrm{BMI}$ (in $\mathrm{Kg} \mathrm{m}^{-2}$ ). Body mass index (BMI) categories were defined using age and sexspecific growth chart by the US Centers for Disease Control and Prevention.

\section{Data verification and analysis}

Questionnaires were checked each day after interviewing and again these were carefully checked after completion of all data collection and coded before entering into the computer. The data was edited if there was any discrepancy. All of the statistical analysis and all other data processing were done by using SPSS 16.0 windows program. For tabular representation Microsoft Word were used. Chi-square was used to test the relationship between independent and dependent variables. Statistical significance was represented by a $P$ value $<0.05$

\section{Results}

Table 1: Percent distribution of nutritional status of the respondents

\begin{tabular}{|c|c|c|}
\hline \multirow{2}{*}{ Nutritional Status } & \multicolumn{2}{|c|}{$\begin{array}{c}\text { Total Respondents } \\
(\mathbf{n = 1 2 0})\end{array}$} \\
\cline { 2 - 3 } & $\mathbf{n}$ & \% \\
\hline Under weight & 54 & 45.0 \\
\hline Healthy weight & 63 & 52.5 \\
\hline Over weight & 3 & 2.5 \\
\hline
\end{tabular}

Table 1 shows the percent distribution of the students by nutritional status. Nutritional status of the students was determined by measuring BMI. Then the BMI was plotted into CDC growth curve (Krebs and Jacobson, 2003). CDC growth curve categorize nutritional status into four categories. Underweight $(<5$ Percentiles curve from growth chart), healthy weight / Normal ( $>5$ to 85 Percentiles), at risk overweight ( $>85$ to 95 Percentiles), and overweight (>95 Percentiles). Regarding the classification of nutritional status, most of respondents $(52.5 \%)$ had healthy weight, $45 \%$ of them were underweight and $2.5 \%$ were overweight.

Table 2. Relationship between nutritional status and predisposing factors

\begin{tabular}{|c|c|c|c|}
\hline $\begin{array}{c}\text { Predisposing } \\
\text { Factors }\end{array}$ & $\begin{array}{c}\text { Percentage } \\
\%\end{array}$ & $\begin{array}{c}\text { Frequency } \\
\mathbf{n}\end{array}$ & $\begin{array}{l}\text { Chi Squire (P-Value) } \\
\text { (Relationship with nutritional status) }\end{array}$ \\
\hline \multicolumn{4}{|c|}{ Number of brothers and/or sisters } \\
\hline No brothers and/or sisters & 20 & 24 & \multirow{4}{*}{0.187} \\
\hline One & 47.5 & 57 & \\
\hline Two & 27.5 & 33 & \\
\hline Three & 5 & 6 & \\
\hline \multicolumn{4}{|l|}{ Age } \\
\hline Below 15 years & 40.83 & 49 & \multirow[t]{2}{*}{0.963} \\
\hline 15 years and above & 59.16 & 71 & \\
\hline \multicolumn{4}{|l|}{ Gender } \\
\hline Male & 55 & 66 & \multirow[t]{2}{*}{0.348} \\
\hline Female & 45 & 54 & \\
\hline \multicolumn{4}{|l|}{ Birth order } \\
\hline $1^{\text {st }}$ birth & 35 & 42 & \multirow{3}{*}{0.003} \\
\hline $2^{\text {nd }}$ birth & 55 & 66 & \\
\hline$>2^{\text {nd }}$ birth & 10 & 12 & \\
\hline \multicolumn{4}{|l|}{ Snacking habit/day } \\
\hline Below two times & 65 & 78 & \multirow[t]{2}{*}{0.000} \\
\hline Above two times & 35 & 42 & \\
\hline \multicolumn{4}{|l|}{ Knowledge level } \\
\hline Poor & 49.17 & 59 & \multirow{3}{*}{0.154} \\
\hline Fair & 35 & 42 & \\
\hline Good & 15.83 & 19 & \\
\hline
\end{tabular}


Table 3. Relationship between nutritional statuses and enabling factors

\begin{tabular}{|c|c|c|c|}
\hline $\begin{array}{c}\text { Enabling } \\
\text { Factors }\end{array}$ & $\begin{array}{c}\text { Percentage } \\
\%\end{array}$ & $\begin{array}{c}\text { Frequency } \\
\text { n }\end{array}$ & $\begin{array}{c}\text { Chi Squire } \\
P \text {-Value } \\
\text { (Relationship with } \\
\text { nutritional status) }\end{array}$ \\
\hline \multicolumn{4}{|l|}{ Type of accommodation } \\
\hline Parents & 99 & 82.5 & \multirow{3}{*}{0.338} \\
\hline Relative & 15 & 12.5 & \\
\hline Hostel & 6 & 5 & \\
\hline \multicolumn{4}{|l|}{ Taking care } \\
\hline Parents & 99 & 82.5 & \multirow{3}{*}{0.007} \\
\hline Relative & 15 & 12.5 & \\
\hline Others & 6 & 5 & \\
\hline \multicolumn{4}{|l|}{ Fathers' occupation } \\
\hline Govt. employee & 17 & 14.17 & \multirow{4}{*}{0.019} \\
\hline Private employee & 12 & 10 & \\
\hline Farmer & 21 & 17.5 & \\
\hline Business or others & 70 & 58.33 & \\
\hline \multicolumn{4}{|l|}{ Mothers' occupation } \\
\hline Govt. employee & 3 & 2.5 & \multirow[t]{2}{*}{0.518} \\
\hline Housewife & 117 & 97.5 & \\
\hline \multicolumn{4}{|l|}{ Fathers' education } \\
\hline Illiterate or primary & 66 & 39 & \multirow{3}{*}{0.371} \\
\hline High school or college & 45 & 63 & \\
\hline Bachelor or others & 9 & 18 & \\
\hline \multicolumn{4}{|l|}{ Mothers' education } \\
\hline Illiterate or primary & 60 & 50 & \multirow{3}{*}{0.007} \\
\hline High school or college & 57 & 47.5 & \\
\hline Bachelor or others & 3 & 2.5 & \\
\hline \multicolumn{4}{|c|}{ Earning person of the family } \\
\hline One & 105 & 87.5 & \multirow{3}{*}{0.028} \\
\hline Two & 12 & 10 & \\
\hline Three & 3 & 2.5 & \\
\hline \multicolumn{4}{|l|}{ Number of family member } \\
\hline Up to 5 member & 90 & 75 & \multirow[t]{2}{*}{0.093} \\
\hline$>5$ member & 30 & 25 & \\
\hline \multicolumn{4}{|l|}{ Money for snacking per day } \\
\hline$<10 \mathrm{BDT}$ & 45 & 37.5 & \multirow{3}{*}{0.020} \\
\hline 11-20 BDT & 63 & 52.5 & \\
\hline$>20 \mathrm{BDT}$ & 12 & 10 & \\
\hline
\end{tabular}

\section{Discussion}

Relationship between nutritional status and predisposing factors

Malnutrition is largely the by-product of insufficient education, low income, poverty, occupation, ignorance, large family size etc. Many factors might relate with nutritional status of children will be presented as follows.

Among the respondents $20 \%$ respondent had no brother brothers and/or sisters, $47.5 \%$ had one, $27.5 \%$ had two and $5 \%$ had three brothers and/or sisters. In this study brother and/or sister were not association with nutritional status $(P=0.187)$. The mean age of respondent in this study was 15.37 years. The results of this study, age was not related with nutritional status
$(P=0.963)$. The proportions of male and female respondents were $55 \%$ and $45 \%$ respectively. This study did not find any significant relationship between gender and nutritional status of children $(P=0.348)$. The same study was done by Aghamolaei (2004) that showed no significant difference in nutritional status between male and female (Aghamolaei and Sobhani, 2004). About half of students (55\%) were second born child, only $35 \%$ was first born child, and $10 \%$ was the third or fourth born child. But birth order was significantly related with nutritional status $(P=0.003)$.

Among the respondents $35 \%$ took snacks more than two times per day. $65 \%$ took snacks one or two time per day. But in present study the relationship between snacking habit and nutritional status $(P=0.000)$. A study in Taheran found that some factors such as snack eating 
habits and breakfast eating habits, in the school were also influence nutritional status. The habit of eating breakfast and stunting were related to educational performance of students. Therefore implementation of food intervention and nutritional education in community may be effective (Alavi et al., 2008). Knowledge level toward nutrition showed no significant relation with nutritional status $(P=0.154)$. Mii (2007) found that, more than half of students had poor level of knowledge $(57.5 \%)$, and $30 \%$ had fair level and only $12.5 \%$ had good level of knowledge, this showed association between knowledge and nutritional status.

\section{Relationship between nutritional status and enabling factors}

More than half of the respondents $(82.5 \%)$ lived with parents, $12.5 \%$ lived with relatives and $5 \%$ lived in hostel when discussing about accommodation type of students. We found a strong significant relation between nutritional status and student accommodation type $(P=0.008)$ at $5 \%$ level of significance. The caretakers were mostly parents $(82.5 \%)$. Relative were also caretakers of few students $(12.5 \%)$. The current study found significant relation between caretakers and nutritional status $(P=0.007)$ at $5 \%$ level of significance. Study in Nepal reported that the students who take care by parents was also significantly associated to nutritional status $(P<0.05)$. Feeding practices affect a child's nutritional status includes adaptation of feeding to the child's abilities responsiveness of the caregiver to the child and selection of an appropriate feeding context (Engle et al., 1999).

Concerning the parents occupations $50 \%$ of the father's occupation were business and $22.5 \%$ were farmer. Majority of the mother's occupation was housewife $(97.5 \%)$. We found significance relation between nutritional status and fathers occupation $(P=0.019)$ but mother occupation was not associated with nutritional status $(P=0.518)$. Parents' education of the majority respondent was in the high school or college (father $63 \%$ and mother 47.5\%). There was association between mother's education and nutritional status $(P=0.007)$. But fathers education had no association with nutritional status $(P=0.371)$. Moradi et al. (2003) reported that education of motherts concerning nutritional requirements of children make them possible to benefit a proper nutritional program. Study in Pakistan by Nabeela et al. (2005) found Prevalence of malnutrition was $42.3 \%$ among children of illiterate mothers as compare to $20 \%$ in those of literate mothers.

When discussing about earning person of the family most of the family had one earning person $(87.5 \%)$ and $10 \%$ had two earning person in family. Earning person in family was significant with nutritional status $(P=0.028)$. Study in Pakistan by Nabeela et al. (2005) also found that children with BMI <5th percentile was $41 \%$ in lower class while in upper class it was $19.28 \%$. In current study $75 \%$ households had less than five or five family members and $25 \%$ households had more than five members. There was no association between family size and nutritional status $(P=0.093)$. A study by Smith and Haddad (2000) examined household size is related to the nutritional status of children. The results of this study found significant association between money for snacking and nutritional status $(P=0.020)$. Most of the students (52.5\%) spent 11-20 for snacks per day.

\section{Conclusions}

Current study was performed to report on nutritional status and related factor among secondary school students. The problem of underweight found $42.5 \%$, among them $25 \%$ was female and $17.5 \%$ was male. It found that among the students the problem of underweight was $45 \%$, and overweight was $2.5 \%$ and healthy weight was $52.5 \%$. In this study we found some independent variable as like birth order $(P=0.003)$, snacking habit $(P=0.000)$, taking care of respondents $(P=0.007)$, fathers' occupation $(P=0.019)$, mothers' education $(P=0.007)$, earning person of the family $(P=0.028)$ and money for snacking $(P=0.020)$ have significant correlation with nutritional status. Improvement in food production, effective economic changes, maternal education, and nutrition education program are few tools to support malnutrition eradication program.

\section{References}

Ahmed, F. 2005. Dietary pattern, nutrient intake and growth of school children in urban Bangladesh. Public Health Nutrition, 1:83-92

Aghamolaei, T. and Sobhani, A. 2004. Anthropometric Evaluation of Nutritional Status. In Primary School Students At Bandar Abbas. Turns Publications. Tehran University of Medical Sciences Publications [cited 2008 Jan 27]. Available from: http://diglib.tums.ac.ir/pub/abstract.asp?magh_id=2 31\&issu=2(3)\&tarikh=2004

Alavi Naeini, S. M.; Jazayeri, S. A.; Moghaddam, B. N.; Afrooz, G. A. and Behboodi, 2008. The effects of taking snacks on the learning ability and educational achievement of elementary school children.1997- 98 [cited 2008 Jan 19]. Available from:

http://diglib.tums.ac.ir/pub/abstract.asp?magh_id=5 $517 \&$ issu $=58(1) \& \operatorname{tarikh}=20$

Child and Mother Nutrition Survey of Bangladesh (CMNSB). 2005. Bangladesh Bureau of Statistics, Planning Division, Ministry of planning, Government of the People's Republic of Bangladesh

Delpeuch, F.; Traissac, P.; Martin-Pre, Y.; Massamba, J. P. and Maire, B. 2000. Economic crisis and malnutrition: socioeconomic determinants of anthropometric status of preschool children and their mothersn in an African urban area. Public Health Nutr., 3:39-47.

Engle, P. L.; Menon, P. and Haddad, L. 1999. Care and Nutrition: Concepts and Measurement. California 
Polytechnic State University, International Food Policy Research Institute, Washington DC, USA. World Development, 27(8):1309-1337.

Govt. of India. 2002. Census of India 2001. Provisional population totals, paper 1of 2001.

Khor, G. L. 2003. Update on the prevalence of malnutrition among children in Asia. Nepal Med. Coll. J., 5(2):13-122.

Krebs, N. F. and Jacobson, M. S. 2003. American Academy of Pediatrics Committee on Nutrition. Prevention of pediatric overweight and obesity. Pediatrics, 112(2):424-30

Mii, A. 2007. Factors related to healthy eating behaviours among first year Mahidol University students, in Salaya, Nakhon Pathom, Thailand. [M.P.H.M. Thesis in Primary Health Care Management] Nakhonpathom: Faculty of Graduate Studies, Mahidol University, 2007.

Moradi-shahrebabak, A. R.; Dorosti-Motlagh, M.; Hoseini, H. and Sadrzadeh, 2003. Assessment of maternal nutritional knowledge, attitude and practice of 6-36 month olds children referred to kerman health centers, 64 (1).

Musaiger, A. O. 2004. Overweight and obesity in the Eastern Mediterranean Region: can we control it? East Mediterr Health J., 10(6):789-793.

Nabeela, F. B.; Rizwana, M.; Muhammad, A. K. and Seema, I. 2010. Impact of Socioeconomic Factors on Nutritional Status in Primary School Children. 2005. J Ayub Med Coll Abbottabad, 22(4) Available from: http://www.ayubmed.edu.pk/JAMC/PAST/224/Nabeela.pdf

Shultz, K. S. and David, J. W. 2005. Measurement Theory in Action, Case Study and Exercises. California state university. Sage publication, London

Smith, L. C. and Haddad, L. 2000. Explaining child malnutrition in developing countries: A cross sectional analysis. Washington: International Food Policy Research Institute. Research Report 111 [cited 2008 Feb 10]. Available from: http://diglib.tums.ac.ir/pub/abstract.asp?magh_id=2 605\&issu $=6$

Suryanarayana, M. H. 2008. Morbidity Profiles of Kerala and All-India: An Economic Perspective. Mumbai: Indira Gandhi Institute of Development Research.

UNICEF. 1990. Strategy for improvement of nutrition of children and women in developing countries. New York: UNICEF

World Health Organization. 2003. STEPS Field manual guidelines for field staff. The WHO step wise approach to surveillance of non communicable diseases (STEPS). WHO/NMH/CCS/03.05. Geneva. p 38-39. 